\title{
DRIVERS AND BARRIERS TO SUSTAINABLE RISK MANAGEMENT (SRM) PRACTICES IN MALAYSIAN ENVIRONMENT SENSITIVE LISTED COMPANIES
}

\author{
Nazliatul Aniza Abdul Aziz' ${ }^{1}$ and Norlida Abdul Manab² \\ ${ }^{1}$ School of Economics, Finance and Banking, Universiti Utara Malaysia. \\ E-mail:nazliatul@uum.edu.my \\ ${ }^{2}$ School of Economics, Finance and Banking, Universiti Utara Malaysia. \\ E-mail: norlida@uum.edu.my
}

\begin{abstract}
Sustainable risk management (SRM) has become the most important managerial trend for business sustainability. Companies have started paying greater attention to adopt SRM towards achieving responsible patterns of consumption and production. Yet little is known about the drivers and barriers to SRM practices. This study aimed to fill this gap by identifying the drivers and barriers to SRM practices among environment sensitive listed companies in Malaysia. Data was collected through a questionnaire survey with 53 respondents and interviews with 3 persons-in-charge of the risk management department from the environment sensitive listed companies in Malaysia. The study revealed that internal factors such as stakeholder pressure and long-term shareholder value motivated the companies to adopt SRM practices. Also, the study found external factors such as corporate governance compliance and regulatory compliance as among the drivers that encourage companies to implement SRM. Nevertheless, the factors which were not perceived as a priority by the board of directors include organisational culture and lack of tools and data that constitute internal barriers to effective implementation of the SRM. The results of this study offer valuable insights to environment-sensitive companies to further understand the drivers and barriers of SRM practices which are essential to becoming sustainable companies.
\end{abstract}

Keywords: sustainability risk management, environmentally sensitive companies, drivers and barriers

\section{ARTICLE INFO}

\section{Article History:}

Received: 14 March 2020

Accepted: 3 July 2020

Published: 31 August 2020 


\section{INTRODUCTION}

Emerging sustainability issues, such as extreme weather events, failure of climate change adaptation, natural disasters and water crises continue to dominate the top ten risks in the Global Risks Report 2019 issued by the World Economic Forum. The twelfth goal of the Sustainable Development Goals (SDGs) developed by the United Nations seek to ensure responsible production and consumption through sustainable business practices. Nevertheless, the twelfth goal cannot be accomplished without any effort by companies to address sustainability risks. Because of these concerns, sustainability risk management (SRM) has become an important tool in the business strategy for managing the wide range of emerging risks arising from sustainability issues (Wijethilake \& Lama, 2018). Fundamentally, SRM triggers companies to contribute to the SDGs, both by minimising possible adverse impacts and capitalize on positive impacts on society and the planet (Burke, Hoistash, \& Hoitash, 2019).

Many organisations have experienced reputational damaging events arising from environmental and social issues. Figure 1 summarises the organisations that failed to manage sustainability issues. The effects of sustainability risks may trigger negative stakeholder reactions, causing interruption to businesses. In this regard, the reputation-damaging events affect stakeholder perceptions on a company and thus causes long-term financial losses (Gatzert \& Schmit, 2016). 


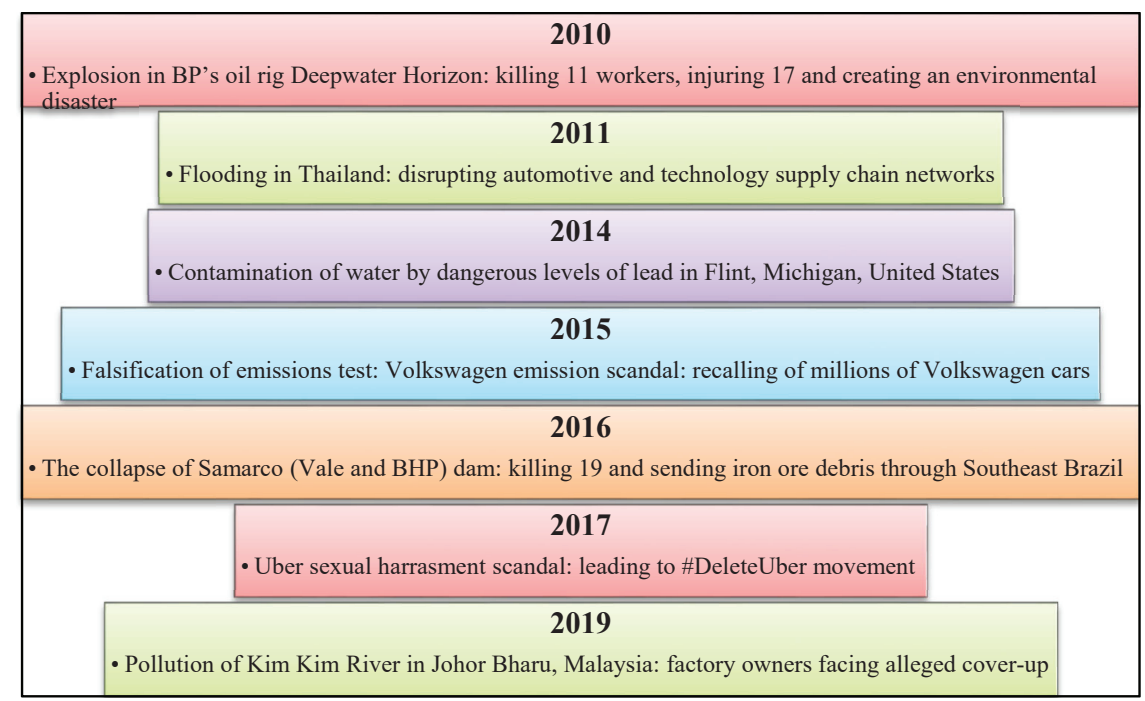

Figure 1: Examples of Organisations

That Have Experienced Sustainability Risk Impacts

Source: Adapted from The Committee of Sponsoring Organizations of the Tread way Commission (COSO) and World Business Council for Sustainable Development (WBCSD) (2018).

Several studies have addressed drivers of SRM practices such as good business practices (Das, 2014), occurrences of unexpected events (Taleb, Goldstein, \& Spitznagel, 2009), stakeholder pressure (Kytle \& Ruggie, 2005), regulatory compliance (Benn, Dunphy, \& Martin, 2009), corporate reputation (Jacob, 2012), operational efficiency (Nigam \& Ramos, 2011), risk-based decision-making improvement (Schulte \& Hallstedt, 2018) and long-term shareholder return (Przychodzen \& Przychodzen, 2013). Shrivastava and Addas (2014) indicated that compliance with corporate governance is critical to ensure that companies pay greater attention to environmental and social aspects.

The World Economic Forum 2019 highlighted how technological advancement had impacted potential range of unforeseen consequences to organisation and changing the risk landscape. In this regards, Dunphy, Benn and Griffiths (2014) stated that technological advancement appears to be an important factor for companies to incorporate sustainability in the risk management process to address changing business environments. Besides, Torres-Ruiz and Ravindran (2017) indicated that sustainability risk tends to disrupt the supply chain of an organisation as global competition increases. 
In short, the driving force for SRM implementation would be from within (internal) or/and outside (external) the organisation. Instead, internal factors such as long-term shareholder returns, corporate reputation, operational efficiency, stakeholder pressure, and good business practice have become the determinant to induce SRM implementation in organisations. External factors, such as corporate governance compliance, regulatory compliance, competition, technological advancements and occurrences of unexpected events also bring call upon companies to implement SRM as part of the steps towards long-term corporate survival.

Nevertheless, companies are also experiencing challenges to engage in SRM practices successfully. Based on past studies, the barriers to SRM that have been identified were the lack of understanding of the major components of effective enterprise risks approaches (Beasley, Branson, \& Hancock, 2011), lack of resources, absence of support from the top management (Marchetti, 2011), organisational culture (McCormack \& Sheen, 2013), the lack of tools in estimating the likelihood of non-financial risks occurrence (Busch \& Hoffmann, 2007) and the lack of attention given to non-financial risks (Wong, 2014). The presence of barriers and the lack of identified drivers are the reasons for organisations to not be aware of the importance of engaging in SRM practices. There are a few studies that examined the applications of sustainability risks in various industries. However, less attention has been given to identify the drivers and barriers companies have been facing in engaging SRM practices. In response, this study aimed to examine the drivers and barriers to SRM practices among environmentally sensitive listed companies in Malaysia. This study contributes to the SRM literature and sought to answer the following research questions:

1. What are the factors that drive environment sensitive companies to engage in SRM practices?

2. What are the barriers to engaging in SRM practices among environment sensitive companies? 


\section{METHODOLOGY}

This study adopted the triangulation method as the research design, which combines two types of data collection methods: questionnaire survey and semi-structured interview. Triangulation refers to the combination of multiple data sources in the study of a similar phenomenon (Sekaran \& Bougie, 2013). This approach assists a researcher to make a comparison between the quantitative statistical findings and the qualitative findings to provide an unabridged understanding of the research problems (Creswell $\&$ Clark, 2017). Few studies have been conducted on risk management that adopted the triangulation method (Kleffner, Lee, \& McGannon, 2003; Manab, Kassim, \& Hussin, 2010). A total of 200 companies from four sectors of environmentally sensitive listed companies in Malaysia were selected based on the stratified random sampling technique. The survey was distributed to corporate-level managers, who are responsible for risk management activities. Of the 200 surveys administered, 53 companies responded to the questionnaires. Concurrently, semi-structured interviews were conducted with the three companies based on their consent in the survey questionnaires to avail the researcher the opportunity to have a face-to-face discussion on SRM practices. The data were limited to only the person who is responsible for risk management activities interviewed from each company.

Environmental sensitive sectors are sectors that pose greater environmental and social footprints. Hence, the management of sustainable risks is given more consideration because these sectors are highly dependent on natural resources in their production processes (Epstein \& Buhovac, 2010). These sectors, which leave huge environmental footprint, include plantations, oil and gas, and construction (Haladu \& Salim, 2017). Due to this, environmentally sensitive sectors have received considerable attention when it comes to the management of sustainability risks (Liew \& Lee, 2012). These sectors are arguably, perilous industry, generally implicate interconnected risks which cause threats to their survival, enormous financial losses, potential vulnerabilities to society and the environment (Adam, 2014). Despite their remarkable contribution to gross domestic product (GDP), environment sensitive companies would not be able to sustain long with poor management of environmental and social risks. In a dynamic and risky environment, more efforts are needed for these sectors to enhance their sustainable growth. 
The data were analysed using the common statistical software SPSS (Statistical Package for Social Science) version 22. The analyses included cross tabulation, and the Chi-square test was used to measure the relationship between multiple variables and to determine whether the frequency distributions of the categorical variables have a significant relationship. The interview data was analysed using thematic analysis which is widely used in qualitative research approaches (Thomas \& Harden, 2008). Thematic analysis provides a style of writing by bringing out the themes to identify similar patterns from the interview answers (Kumar, 2011) in order to provide a rich set of data (Braun \& Clarke, 2006).

\section{Quantitative Results}

Table 1 below presents the result of cross-tabulation between the type of sectors and SRM drivers. The results show that good business practice is the most critical factor for plantation companies (100\%) to engage in SRM practices, followed by manufacturing companies (76.2\%). Meanwhile, corporate governance compliance has been found as the main motivating factor for oil and gas companies $(90 \%)$ and construction companies $(89 \%)$ to engage in SRM practices. The result of the Chi-square test showed that there is a 5 percent significance level pertaining to the relationship between corporate governance compliance and the type of sector.

Table 1: SRM Drivers According to Sector

\begin{tabular}{|c|c|c|c|c|c|}
\hline \multirow[b]{2}{*}{ SRM Drivers } & \multicolumn{5}{|c|}{ Percentage According to the Type of Sector } \\
\hline & Manufacturing & Construction & $\begin{array}{l}\text { Oil \& } \\
\text { Gas }\end{array}$ & Plantation & $P$-value \\
\hline Good business practice & 76.2 & 61.1 & 70 & 100 & 0.424 \\
\hline $\begin{array}{l}\text { Improve risk-based } \\
\text { decision-making }\end{array}$ & 76.2 & 72.2 & 50 & 75 & 0.500 \\
\hline Comply with regulatory & 66.7 & 66.7 & 60 & 50 & 0.912 \\
\hline $\begin{array}{l}\text { Technological } \\
\text { advancement }\end{array}$ & 9.5 & 0 & 0 & 25 & 0.167 \\
\hline $\begin{array}{l}\text { Corporate governance } \\
\text { compliance }\end{array}$ & 52.4 & 89 & 90 & 50 & $0.028^{* *}$ \\
\hline $\begin{array}{l}\text { Occurrence of unexpected } \\
\text { risk events }\end{array}$ & 33.3 & 11.1 & 30 & 25 & 0.425 \\
\hline Corporate reputation & 14.3 & 16.7 & 20 & 50 & 0.410 \\
\hline $\begin{array}{l}\text { Board of Directors }(B O D) \\
\text { request }\end{array}$ & 23.8 & 55.6 & 40 & 25 & 0.700 \\
\hline Operational effectiveness & 57.1 & 61.1 & 50 & 25 & 0.601 \\
\hline
\end{tabular}




\begin{tabular}{lccccc} 
Long-term shareholder & 43 & 11.1 & 30 & 0 & $\mathbf{0 . 0 8 6}^{*}$ \\
value & & & & & \\
Competition & 9.5 & 4.8 & 0 & 0 & 0.699 \\
Stakeholder pressure & 0 & 0 & 0 & 25 & $\mathbf{0 . 0 0 6}{ }^{* * *}$ \\
Value added function & 14.3 & 22.2 & 30 & 50 & 0.414 \\
\hline Notes: ${ }^{* *} p<0.01,{ }^{* *} p<0.05 ;{ }^{*} p<0.1$ & & & & &
\end{tabular}

The results also indicate that there is a strong relationship between stakeholder pressure and the type of sector at the one percent (1\%) significance level. This is probably because only the plantation sector $(25 \%)$ mentioned that the stakeholder pressure triggered the company to engage in SRM practices. Besides, this study also found a positive relationship between long-term shareholder value and type of sector at the 10 percent significance level.

Table 2 presents the result of the cross-tabulation between the type of sectors and SRM barriers. Organisational culture was found as the most cited barrier for the oil and gas sector (90\%) to engage in SRM practices. The results show that there is a positive relationship at the 1 percent significance level between organisational culture and the type of sector.

Table 2: SRM Barriers According to Sector

\begin{tabular}{|c|c|c|c|c|c|}
\hline \multirow[b]{2}{*}{ SRM Barriers } & \multicolumn{4}{|c|}{ Percentage according to the Type of Sector } & \multirow[b]{2}{*}{ P-Value } \\
\hline & Manufacturing & Construction & $\begin{array}{l}\text { Oil \& } \\
\text { Gas }\end{array}$ & Plantation & \\
\hline Lack of tools & 33.3 & 16.67 & 0 & 50 & $0.095^{*}$ \\
\hline $\begin{array}{l}\text { Lack appropriate } \\
\text { technology }\end{array}$ & 14.3 & 11.1 & 0 & 25 & 0.531 \\
\hline $\begin{array}{l}\text { Lack of sufficient } \\
\text { resources }\end{array}$ & 43 & 39.9 & 40 & 50 & 0.978 \\
\hline $\begin{array}{l}\text { Lack of support from top } \\
\text { management }\end{array}$ & 9.5 & 16.7 & 30 & 25 & 0.529 \\
\hline $\begin{array}{l}\text { Lack of understanding } \\
\text { of major components of } \\
\text { effective enterprise risk } \\
\text { approach }\end{array}$ & 66.7 & 38.9 & 60 & 25 & 0.215 \\
\hline $\begin{array}{l}\text { Lack of risk management } \\
\text { expertise }\end{array}$ & 47.6 & 55.5 & 20 & 75 & 0.194 \\
\hline $\begin{array}{l}\text { Not perceived as a priority } \\
\text { in the organisation }\end{array}$ & 33.3 & 55.5 & 50 & 0 & 0.159 \\
\hline Organisational culture & 28.6 & 61.1 & 90 & 25 & $0.007^{* * *}$ \\
\hline
\end{tabular}


Furthermore, the result also shows that there is a relationship between the lack of tools and the type of sector at the 10 percent significance level. Only the oil and gas sector reported that they have sufficient tools for the effective implementation of the SRM program, whereby none of them ( $0 \%)$ mentioned tools as their barrier.

Meanwhile, the lack of understanding on major components of effective enterprise risks approach $(66.7 \%)$ is the main barrier to SRM adoption in the manufacturing sector. In addition, the lack of risk management expertise $(75 \%)$ is the main obstacle to adopt SRM programmes in the plantation sector. However, the results show that there is no relationship between the lack of understanding on the major components of the effective enterprise risks approach, risk management expertise and type of sector.

\section{Qualitative Results}

Three companies participated in the qualitative part of the study. The interviews were conducted with the head of the department of risk management (HOD-RM) from all the three companies. Company A is a national automobile manufacturer that is involved in automobile design, manufacturing, marketing and sales whilst Company B is a construction company involved in the field of engineering, quarrying, township and property development. Company $\mathrm{C}$ is one of the biggest producers of Malaysian crude palm oil and the world's third largest plantation operator. Table 3 depicts the important drivers that motivated these companies to engage in SRM practices.

Table 3: SRM Drivers

\begin{tabular}{ccccc} 
Reason & $\begin{array}{c}\text { Corporate } \\
\text { Governance } \\
\text { Compliance }\end{array}$ & $\begin{array}{c}\text { Regulatory } \\
\text { compliance }\end{array}$ & $\begin{array}{c}\text { Stakeholder } \\
\text { pressure }\end{array}$ & $\begin{array}{c}\text { Long term } \\
\text { shareholder } \\
\text { value }\end{array}$ \\
\hline A & $\sqrt{ }$ & & $\sqrt{ }$ & \\
\hline B & $\sqrt{ }$ & & $\sqrt{ }$ & \\
\hline C & $\sqrt{ }$ & $\sqrt{ }$ & & \\
\hline
\end{tabular}

All the case companies (A, B and C) implemented SRM practices to comply with the Malaysian Code of Corporate Governance 2012 and the Bursa Malaysia Listing Requirements to ensure an effective risk management system and facilitate sustainability practices, as stated below: 
"Partly we did because we want to comply with the corporate governance standards and listing requirements. We have to ensure that our company follows the corporate governance requirements and we are almost there since".

(HOD-RM, Company A)

"We have a Malaysian Code of Corporate Governance (MCCG) and Bursa Malaysia listing requirements that we need to comply with and all of these have supported our risk management programme".

(HOD-RM, Company B)

"Since we are a listed company, of course we need to comply with corporate governance codes".

(HOD-RM, Company C)

Like other companies in the plantation sector, Company $\mathrm{C}$ has to follow many guidelines and standards to ensure safety, health and welfare of its employees at the production site and protect them from environmental malfeasance. Besides, Company C engages in SRM practices not only for corporate governance compliance, but also to comply with the European Union (EU) sustainability requirements, to penetrate the international markets. HOD-RM of Company A and B expressed their concerns:

"Our business operations are monitored by the local authorities such as the Department of Environment (DOE) and the Department of Occupational Safety and Health Malaysia (DOSH)”.

(HOD-RM, Company B)

"In addition, we also need to fulfil the requirements by the International Sustainability Carbon Certification (ISCC). This applies to compliance and to meet our company's best practices. Well, to penetrate the European Union (EU) market, we are required to develop sustainability guidelines, strategies and policies to meet their certification and standards. Otherwise, the penalties will be imposed if we cannot satisfy the essential requirements".

(HOD-RM, Company C) 
Company A and B claimed that compliance was not the only factor that motivated them to implement SRM. The other factors were to address stakeholder interests and to enhance long-term shareholder value. The HOD-RM (Company A) and HOD-RM (Company B) added:

"Besides, we need to address our stakeholder's interest and maintain our branding since now a lot of competitors are coming in. External stakeholders including investors, consumers and governments to a quite large extent are very concerned with sustainability issues right now".

(HOD-RM, Company A)

"We engage our key stakeholders in addressing environmental and social issues because we need to make sure that every risk arising from our business activities does not affect our goals and the stakeholder's interest. In other words, our company did this to enhance our shareholder value in the long run".

(HOD-RM, Company B)

It appeared that the companies are under great pressure to engage in SRM practices not only as a consequence to enhance their long-term shareholder value but also to satisfy their customers and stakeholders. In other words, the stakeholders exert pressure on companies to implement SRM, which could lead to positive effects on shareholder value.

Despite the drivers that motivated the companies to engage in SRM practices, there are barriers to SRM mentioned by the interviewees. Table 4 shows the barriers to engage in SRM practices faced by the three case companies. The lack of tools and data, not perceived as a priority at the board level, and organisational culture were the barriers for companies to implement SRM effectively. 
Table 4: SRM Barriers

\begin{tabular}{cccc} 
Barrier & $\begin{array}{c}\text { Organisational } \\
\text { culture }\end{array}$ & $\begin{array}{c}\text { Not perceived as } \\
\text { priority }\end{array}$ & $\begin{array}{c}\text { Lack of tools and } \\
\text { data to quantify } \\
\text { emerging risks }\end{array}$ \\
\hline A & & $\sqrt{ }$ & $\sqrt{ }$ \\
\hline Company & $\sqrt{ }$ & $\sqrt{ }$ & \\
\hline
\end{tabular}

Company A and B which had fully implemented risk management programmes across their organisation indicated that emerging sustainability risks were not given much priority by the management due to the lack of risk management tools and lack of risk awareness at the board level. This was expressed by the HOD-RM of Company A and Company B:

"If you ask me whether the emerging risk process is part of it, we have not really thoroughly assessed and discussed on the emerging risks."

(HOD-RM, Company A)

"Less attention was given on the unknown risks especially by the board. And I think that is because our management and the board are unaware of the emerging sustainability issues".

(HOD-RM, Company B)

Other important barriers raised by two of the companies (B and C) were organisational culture. The HOD-RM of Company B and C commented that:

"Organisational culture is fundamental in any changes in risk management programs. Definitely, it takes time for us to promote an organisational culture properly".

(HOD-RM, Company B)

"I would say before 2008, our risk management culture was very strong. However recently it was getting flawed due to misuse of authority and other forms of corruption. I suggest that if you can remove politicians from the board of directors, this situation will never happen”.

(HOD-RM, Company C) 
The appointment of board of directors among individuals that have political interests might lead to exploitation of power and responsibility. The company would face greater corruption risks when corporate ownership and controls are transferred to individuals with multiple interests. Such a conflict of interest may result in corrupt behaviour and result in a weak organisational risk culture. In summary, the top management needs to lead by example to be able to cultivate a positive risk culture that enables a high standard of governance.

The HOD-RM of Company B mentioned that:

"I can say that our management is not aware of the fact that they are currently part of the risk management programme. They simply pass their responsibility to me, while risk management is the responsibility of everyone. People on the production site normally just want to reach their goal and are not aware of the risks".

(HOD-RM, Company B)

In conclusion these findings suggest that corporate governance compliance, regulatory compliance, stakeholder pressure and long-term shareholder value are the main factors that motivated these companies to engage in SRM practices. Despite the drivers mentioned, it is acknowledged that organisational culture is not perceived as a priority and the lack of data and tools are the major barriers to engage in SRM practices.

\section{DISCUSSIONS}

The current study was set out to identify the drivers and barriers to SRM practices among environmentally sensitive listed companies in Malaysia. The results indicate that the implementation of SRM practices are motivated by both internal and external factors. Encouragingly, across the organisations, more drivers than barriers to SRM practices were identified. In general, the internal factors exerted greater pressure on the companies than external factors. The internal factors that motivated the companies to implement SRM practices are good business practices, improved riskbased decision-making, regulatory compliance, operational effectiveness, 
requested by the BOD, long-term shareholder value, stakeholder pressure and corporate reputation. On the other hand, the external factors that motivated the environmentally sensitive companies to implement SRM are corporate governance compliance, compliance with laws and regulations, occurrence of unexpected events, and technological advancement.

The findings also found that the need to comply with the Malaysian Code of Corporate Governance 2012 (MCCG 2012) had created responsiveness among the companies to engage in SRM practices. Indeed, MCCG 2012 is applied to the public listed companies to enhance their environmental and social performance. The companies that have been considered successful in implementing SRM are not only being driven by corporate governance compliance, but also by good business practices. In addition, the findings from this study showed that meeting stakeholders' interests ultimately helps to retain support from the stakeholders and build a good relationship between companies. This shows that stakeholder engagement is crucial to a company's success in the long-term. According to Kim, Wagner, and Colicchia (2019), stakeholders' demand on companies to take full responsibility for the effects of their business activities, and failure to resolve sustainability risks can lead to negative reactions from stakeholders.

With respect to the second research question, the findings indicate that the barriers to SRM practices experienced by organisations tend to be internal. The factors such as not perceived as a priority by the board of directors, organisational culture and lack of tools and data hindered organisations to implement SRM practices. Apparently, the findings showed that failure of the board of directors to deliver duty of care to stakeholders indicates a weak organisational culture. A strong organisational culture is a key indicator to good governance. According to a study done by Hossain, Sobhani, Omar, Mohamad, and Said (2019), good governance is critical to the performance and competitiveness of a company. Besides, the findings showed that the environmentally sensitive companies experienced lack of tools to quantify emerging sustainability risks. According to Hubbard (2009), risks are often evaluated through historical data analysis. However, emerging risks related to sustainability issues are difficult to be quantified using historical precedence. In light of evolving sustainability issues, sustaining a business requires a strong foundation of the economic, 
environmental and social aspects to address risks and realise the SDGs. Sustainable business practices is becoming a norm for companies to create reputational advantage and maximising long-term economic benefits (Nair \& Wahh, 2017). Supporting this view, engaging in SRM practices reflects a long-term commitment by companies to achieve sustainable business practices in realising the SDGs.

\section{CONCLUSIONS}

This study provides further insights on the drivers and barriers to engage in SRM practices among environment sensitive companies in Malaysia. The results of the analyses highlight the internal and external drivers that motivate companies to implement SRM programmes, which comprise long-term shareholder value, good business practices, corporate reputation, corporate governance compliance and stakeholder pressure whilst internal barriers to SRM practices include not perceived as a priority, organisational culture and the lack of tools and data. As revealed in the study outcomes, it is important for organisations to realise the factors that drive companies to engage in SRM practices, whether driven by internal factors or forces from external stakeholders. Despite the numerous contributions highlighted, there are several limitations to this study. Firstly, it has been difficult to find the literature on SRM practices in Malaysian listed companies. Another limitation is the population and sample of survey respondents are only targeted on the environment sensitive industries. The future direction of this study is to look at the relationship between the maturity level of SRM practices and company survival across all sectors of listed companies in Malaysia. Finally, managing sustainability risk is an area of continuing relevance to society. Therefore, SRM is critical for companies to responsibly perform their duties to society.

\section{REFERENCES}

Adam, I. S. (2014). An empirical investigation of the efficiency, effectiveness and economy of the Nigerian National Petroleum Corporation's management of Nigeria's upstream petroleum sector (Doctoral dissertation, Robert Gordon University). 
Beasley, M., Branson, B., \& Hancock, B. (2016). The State of Risk Oversight: An Overview of Enterprise-Wide Risk Management Practices Overview. Retrieved from https:/erm.ncsu.edu/az/erm/i/chan/ library/aicpa_erm_research_study_2016.pdf.

Benn, S., Dunphy, D., \& Martin, A. (2009). Governance of environmental risk: New approaches to managing stakeholder involvement. Journal of Environmental Management, 90(4), 1567-1575.

Birkel, H. S., Veile, J. W., Müller, J. M., Hartmann, E., \& Voigt, K. I. (2019). Development of a risk framework for Industry 4.0 in the context of sustainability for established manufacturers. Sustainability, 11(2), 384.

Braun, V., \& Clarke, V. (2006). Using thematic analysis in psychology. Qualitative Research in Psychology, 3(2), 77-101.

Burke, J. J., Hoitash, R., \& Hoitash, U. (2019). The heterogeneity of boardlevel sustainability committees and corporate social performance. Journal of Business Ethics, 154(4), 1161-1186.

Busch, T., \& Hoffmann, V. H. (2007). Emerging carbon constraints for corporate risk management. Ecological Economics, 62(3), 518-528.

Committee of Sponsoring Organizations of the Treadway (COSO) \& World Business Council for Sustainable Development (WBCSD). (2018). Enterprise Risk Management: Applying enterprise risk management to environmental, social and governance-related risks. Retrieved from https://www.wbcsd.org/bn68.

Creswell, J. W., \& Creswell, J. D. (2017). Research design: Qualitative, quantitative, and mixed methods approaches. London, UK: Sage Publications.

Das, A. B. (2014). Ethical consequences: Treatment of stakeholders in capitalistic approach and cooperative approach to business. European Journal of Business and Management, 6(23), 64-66. 
Dunphy, D. C., Benn, S., \& Griffiths, A. (2014). Setting the agenda for corporate sustainability. Organizational Change for Corporate Sustainability, Understanding Organizational Change. Routledge, Abingdon, Oxon, 3-33.

Epstein, M. J., \& Buhovac, A. R. (2010). Solving the sustainability implementation challenge. Organizational Dynamics, 39(4), 306-315.

Gatzert, N., \& Schmit, J. (2016). Supporting strategic success through enterprise-wide reputation risk management. The Journal of Risk Finance, 17(1), 26-45.

Haladu, A., \& Salim, B. B. (2017). Sustainability reporting by firms in the Nigerian economy: Social versus environmental disclosure. Journal of Accounting and Finance in Emerging Economies, 3(2), 87-112.

Hossain, A., Sobhani, F. A., Omar, N., Mohamad, N., \& Said, J. (2019). Corporate governance, risk management and ethical investment: Evidence from banking industries. International Journal of Financial Research, 10(5), 126-137.

Hubbard, D. W. (2009). The failure of risk management: Why it's broken and how to fix it. New Jersey: John Wiley \& Sons.

Jacob, C. K. (2012). The impact of financial crisis on corporate social responsibility and its implications for reputation risk management. Journal of Management and Sustainability, 2(2), 259-275.

Kim, S., Wagner, S. M., \& Colicchia, C. (2019). The impact of supplier sustainability risk on shareholder value. Journal of Supply Chain Management, 55(1), 71-87.

Kleffner, A. E., Lee, R. B., \& McGannon, B. (2003). The effect of corporate governance on the use of enterprise risk management: Evidence from Canada. Risk Management and Insurance Review, 6(1), 53-73.

Kumar, R. (2011). Research methodology: A step-by-step guide for beginners ( $3^{\text {rd }}$ ed.). London: Sage Publications Limited. 
Kytle, B., \& Ruggie, J. G. (2005). Corporate social responsibility as risk management: A model for multinationals (Kennedy School of Government Working Paper No. 10). Cambridge, MA: John F. Kennedy School of Government, Harvard University.

Liew, K. C., \& Lee, C. K. (2012). Modelling and risk management in the offshore and marine industry supply chain. International Journal of Engineering Business Management, 4(1), 1-7.

Manab, N. A., Kassim, I., \& Hussin, M. R. (2010). Enterprise-wide risk management (EWRM) practices: Between corporate governance compliance and value. International Review of Business Research Papers, 6(2), 239-252.

Marchetti, A. (2012). Enterprise risk management best practices: From assessment to ongoing compliance. Hoboken, New Jersey: John Wiley \& Sons, Inc.

McCormack, P., \& Sheen, A. (2013). Operational risk: Back on the agenda. Journal of Risk Management in Financial Institutions, 6(4), 366-386.

Nair, P. B., \& Wahh, R. W. B. (2017). Strategic CSR, reputational advantage and financial performance: A framework and case example. World Review of Science, Technology and Sustainable Development, 13(1), $37-55$.

Nigam, P., \& Ramos, M. (2011). Sustainability risk management. In J. Reuvid (Ed.), Managing business risk - A practical guide to protecting your business ( ${ }^{\text {rd }}$ ed.). London (UK) and Philadelphia (USA): Kogan Page.

Przychodzen, J., \& Przychodzen, W. (2013). Corporate sustainability and shareholder wealth. Journal of Environmental Planning and Management, 56(4), 474-493.

Schulte, J., \& Hallstedt, S. (2018). Company risk management in light of the sustainability transition. Sustainability, 10(11), 41-37. 
Sekaran, U., \& Bougie, R. (2013). Research methods for business: A skill building approach ( $5^{\text {th }}$ ed.). India: John Wiley \& Sons Ltd.

Shrivastava, P., \& Addas, A. (2014). The impact of corporate governance on sustainability performance. Journal of Sustainable Finance \& Investment, 4(1), 21-37.

Taleb, N. N., Goldstein, D. G., \& Spitznagel, M. W. (2009). The six mistakes executives make in risk management. Harvard Business Review, 87(10), 78-81.

Thomas, J., \& Harden, A. (2008). Methods for the thematic synthesis of qualitative research in systematic reviews. BMC Medical Research Methodology, 8(1), 45.

Torres-Ruiz, A., \& Ravindran, A. R. (2018). Multiple criteria framework for the sustainability risk assessment of a supplier portfolio. Journal of Cleaner Production, 172, 4478-4493.

Wijethilake, C., \& Lama, T. (2019). Sustainability core values and sustainability risk management: Moderating effects of top management commitment and stakeholder pressure. Business Strategy and the Environment, 28(1), 143-154.

Wong, A. (2014). Corporate sustainability through non-financial risk management. Corporate Governance, 14(4), 575-586.

World Economic Forum. (2019). The Global Risks Report 2019 14th Edition. Retrieved from http://www3.weforum.org/docs/WEF_Global_Risks Report_2019.pdf 